\title{
Is Facebook a Suitable Tool in Modern World Technology for Active Learning in as Regards $21^{\text {st }}$ Century Learning?
}

\author{
https://doi.org/10.3991/ijet.v12.i10.6976 \\ Orawit Thinnukool \\ Chiang Mai University, Chiang Mai, Thailand \\ orawit.tecmu.ac.th \\ Noodchanath Kongchouy \\ Prince of Songkla University, Hat Yai Campus, Songkhla, Thailand.
}

\begin{abstract}
The style of learning nowadays has been changed, especially for students of Generation Z. A suitable technique for teaching courses needs to be adopted to improve the learning effectiveness of students. Modern technology and an up-to-date tool affect student learning abilities, especially in 21 st century learning, which requires students to learn by doing.

Tools and environment are aspects that can encourage students to have high learning efficiency. Facebook, a powerful medium, was used as a tool to support students' learning. This study aims to conduct research and test learning efficiency and student satisfaction in the course of rapid application development by setting two environments in classrooms by using a difference tool. The experiment found that the two environments had two different outcomes, which may suggest that setting up an active learning environment by using Facebook in classrooms can prove to be beneficial. Although the new technology of using Facebook provided higher learning outcomes, it was not found to affect all students. Interesting results and implications for research are discussed.
\end{abstract}

Keywords-active learning, Generation Z, learning effectiveness, students' satisfaction

\section{Introduction}

Learning by doing is a well-known phrase that people understand, especially in the modern classroom. Thai education encourages schools and universities to use new teaching techniques for $21 \mathrm{st}$ century learning. The $21 \mathrm{st}$ century learning concept is about learning by doing, which allows students to have logical skills to solve problems, apply knowledge to new situations, analyze information, make decisions, and comprehend new ideas [1]. According to Bloom's taxonomy of learning domains, skills can be categorized as mental skills (knowledge), affective skills: growth in feelings or emotional areas (attitude or self), and psychomotor skills: manual or physical skills [2]. 
Thus, course and learning style are very important aspects that let students acquire the skills mentioned above.

Nowadays, education for undergrads or high-school students has changed, for example the learning style, behavior, time, program, and new technology. Behavior of students is one of the important points to consider for an instructor to research for useful results, thus allowing such an instructor to design suitable courses. The main objective of the program is to provide a plan for education, which helps students acquire an understanding of technical skills. The old style of setting up a learning environment is not appropriate for Generation $\mathrm{Z}$ students nowadays. Generation Z, or Gen $Z$, refers to the group of people born between 1990 and the mid-2000s or the present day. Generation $\mathrm{Z}$ students are complex in terms of thinking, character, and behavior [3].

Moreover, the distinguishing characteristic of Gen $\mathrm{Z}$ in terms of social environment is access to instant communication and the world of social networks perceived without time and space limit [4]. Technology, nowadays, has the potential to encourage them to be attentive and enhance the learning performance and learning motivation. A study by Waldeck shows that the use of technology has encouraged students to develop an increased motivation to learn [5]. However, overuse of technology in the class may directly affect students when they perceive it from an instructor [6]. Suitable technology for instructors to use in a classroom setting is important in terms of appropriate learning style. Thus, a balance is needed between styles of learning and use of technology in classrooms for students to benefit fully from both.

Learning style is a point to consider at this time, when Gen $\mathrm{Z}$ is becoming the current generation. The new style that universities and high schools are using in their education is called "active learning," which is a form of collaboration between instructors and students or between students in groups of different sizes. This style improves access to information, and increases ways in which material is provided to students; it uses equipment in classrooms and follows nontraditional forms of progress assessment [7].

This learning style has been applied together with ICT in a variety of courses and created significant outcomes [8]. Apart from a variety of tools, it is the advent of new technologies that provides direct enforcement to students in classrooms, which directly affects the learning process. Many instructors have accepted that tools which help them to teach their courses are a helpful substitute for the usual practices.

Nowadays, technology has tools that drive teaching methods in classrooms. For example, a learning management system (LMS) helps instructors provide the course syllabus, paper documents, and presentation slides, and collect students' assignments electronically [9]. Furthermore, there is hardware that provides a suitable environment for active learning. For example, a clicker is a device that helps instructors find out students' responses, which encourages active learning [10]. Similarly, a color card is used to monitor students' responses in regular classrooms (similarly to a clicker). A variety of devices can be used to create a beneficial environment for active learning, but a suitable style for students must be chosen, and that depends on the class level. For example, at high school level, games may be suitable for students. With 
games, students automatically learn their lessons as they are motivated through sound, picture, and animation, and their perception is increased.

The next level of students is the undergraduate level: this level consists of students who enroll in a university course. According to several sources, a Gen $\mathrm{Z}$ person will grow up in a highly sophisticated media and computer environment [11]. Gen Z and, especially, undergraduate students have a special nature. Several researchers confirm that electronic devices reinforce Gen Z students' interest in the content [12][13][14]. This is another reason to adopt the active learning style. A powerful tool that is popular nowadays, called "Facebook," provides a communication channel between instructors and students, and supports active leaning [15]. Several researchers agree that Facebook as a tool increases the learning performance [16][17]. Moreover, the positive impact of Facebook is evident in that it can centralize learning, for example, when it comes to course assignments, group work, group projects, sharing of materials, as well as enabling of instructors to monitor students' discussions on the Facebook group page [18][19].

In the absence of learning performance monitoring, student satisfaction is the indicator that tells the instructor whether or not the students, especially Gen Z students, appreciate the material or learning style. When students have high levels of satisfaction in the learning process, they pay attention to the instructor or the study equipment [20], which confirms the link between student satisfaction and learning performance [21]. For many reasons, Facebook has been encouraged to be used as a new tool for setting classrooms for active learning. Therefore the objective of this research study was to find out which learning style is appropriate for students' nature and course content. The researchers believe that course content and learning style are key points for setting a suitable learning environment for students as Rutz claims that learning style affects the grade point average (GPA) [22]. For this reason, the authors hope that students' skills such as learning potential, learning outcome, creativity and innovation, critical thinking, and problem solving will improve.

In this study, the setup of an active learning environment while teaching the subject of Rapid Application Development was examined [23]. The App Inventor that was used during this course is an application created by the Massachusetts Institute of Technology. It is an online (cloud-based) block editor which is used to build and design each function to run the application. Without any prior programming and design skills, students can learn how to develop an application. A suitable style of learning will provide a powerful learning curve, and give a high level of satisfaction and learning effectiveness. Two groups of students were created for the research experiment to test the learning effectiveness of active learning and traditional learning styles. The Thai education system mainly uses the traditional learning style. The question is whether or not the Thai education system utilizes a suitable style of learning for students.

Therefore, in this study, both the learning environments (traditional learning and active learning) were set up and tested. Based on the study, it is the grade point average (GPA) of the students that shows their learning performance. Students who have high GPA would have higher learning performance than students who have low GPA [24]. The results of the study are considered when managing a learning environment 
(learning style) set up in teaching the subject of information technology. The questions raised for this study are the following:

1. Do active learning styles influence the GPA score more positively than traditional learning styles?

2. Is the student satisfaction level in active learning set higher than in the traditional learning style?

\subsection{Theories of Learning and Active learning}

There are various theories of learning such as behaviorism, cognitivism, constructivism, design-based, humanism, etc. which explain how to create knowledge [25][26]. With regard to the active learning style, Bloom's taxonomy is a useful theory and can be applied in the active learning style in this research study. Bloom explains the steps of learning when students study something: the knowledge germinates from the cognitive domain (knowledge-based). Essentially, Bloom's taxonomy is associated with constructivism theory which contains three domains: cognitive domain (knowledge-based), affective domain (emotion-based), and psychomotor domain (action-based), covering the learning objectives in the active learning style [27]. The cognitive domain contains the processes of remembering, understanding, applying, analyzing, evaluating, and creating, all of which encourage the student to acquire intellectual and problem-solving skills. The affective domain is associated with students' emotional reactions and their ability to feel empathetically, and is aimed at developing their attitudes, emotions, and feelings. The five levels in the affective domain are receiving, responding, valuing, organizing, and characterizing.

On the other hand, the psychomotor domain (action-based) skills describe the ability to physically manipulate a tool or instrument. The three domains of Bloom's taxonomy strongly support the active learning style, especially "learning in action."

The active learning that the instructors applied to the educational system has three styles as follows:

1. Active learning is the style of learning which encourages and challenges the student's thinking using real-life situations in a classroom setup. Various tools as well as curricula can help the students during the class and encourage them [10].

2. Situated learning is associated with social-constructivist thinking that sees learning as "an active process of building knowledge and skills within a supportive group." This learning encourages students to communicate, interact, and collaborate, which builds knowledge and skills [28].

3. Problem-based learning is the learning style that requires the student to solve problems.

Interaction between the student and the other people in the class may provide practice of communication [29].

The active learning style is widely used; several researchers have applied active learning with nursing students [30]. Different times, different wards, and setting of 
suitable learning plans in each year of the student are the steps of setting an active learning environment. Participation is key for setting a clinical practicum.

In addition, Canaleta applied the active learning style to improve the low performance of students by using real scenarios, and project-based collaborative learning utilized social networks and blogs to improve learning efficiency [31]. Collaboration on active learning involves reviews and evaluation from instructors and other students in the class. For this style, students who fall behind learn from others by participation.

With regard to using active learning together with electronic devices, which Park studied about in intensive courses, especially in university curricula, it may lead students to success and encourage them to have learning efficacy [32]. Interestingly, from the explanation of the instructor as regards the techniques of the active learning style [33][34], two styles can be identified as useful for Gen Z students, and they are outlined here:

1. Cooperative learning: this style involves students working in groups, which helps them learn from the other members of the group. The benefit from this style is derived the maximum particularly when students work together over time or on difficult projects or exercises.

2. Share and pair: in this style, students are paired, which makes them accept each other's opinion and lets them share knowledge. Moreover, this style hones their argumentative skills.

\section{Methods}

\subsection{Sample}

The population for this study was second-year students of College of Art, Media, and Technology. A sample was selected from students who enrolled in the RAD course in the second semester of 2015. The sample was picked randomly from the six groups (25-30 persons per group, a total of 168 students) and put into two groups, where the first group used active learning and the second group used traditional learning. The numbers of the two groups are shown in Table 1.

Table 1. Sample of Experimental Groups

\begin{tabular}{|l|c|c|c|}
\hline \multicolumn{1}{|c|}{ Group } & Male & Female & Total \\
\hline Active learning & 15 & 9 & 24 \\
Traditional learning & 18 & 7 & 25 \\
Total & 33 & 16 & 49 \\
\hline
\end{tabular}

To ensure that the two groups do not differ in terms of GPA and gender, ANOVA $\mathrm{F}$ test (shown in the result of the test in appendix Table I and Table II, respectively) was used, and it confirmed that the samples were similar. The samples were selected, and the names of the students who were samples were indicated in the name lists so 
that they did not know if they were samples; this was done in order to have a fair representation in the sample groups.

\subsection{Experimental Design}

In this research study, two sample groups were studied and the impacts of two learning styles were compared. The active learning group was set to be the experimental group and the traditional learning group was the control group. Table 2 shows the details of the setup in each group. The experimental design for this research used the posttest-only control group design style to measure the outcome of active learning. Figure 1 is the diagram for the experimental design.

Table 2. Criteria of Learning Details for Each Group

\begin{tabular}{|l|l|l|}
\hline \multicolumn{1}{|c|}{ Criterion } & \multicolumn{1}{c|}{ Active Learning } & \multicolumn{1}{c|}{ Traditional Learning } \\
\hline 1. Channel to public content material & Online (Facebook) & Classroom \\
\hline 2. Learning & Pair & Individual \\
\hline 3. CASE tools & App Inventor & App Inventor \\
\hline 4. Leader of learning & Student / Instructor & Instructor \\
\hline 5. Examination & Paper-based & Paper-based \\
\hline
\end{tabular}

E-group is the experimental group that was collected from the sample (R) to be used for treatment (active learning) for the study style (X), which was then evaluated by the test $(\mathrm{O} 2 \mathrm{E})$, whereas C-Group is the control group which was selected from the sample $(\mathrm{R})$ to be the control group and which used the traditional learning style (Y) followed by evaluation by the test $(\mathrm{O} 2 \mathrm{C})$.

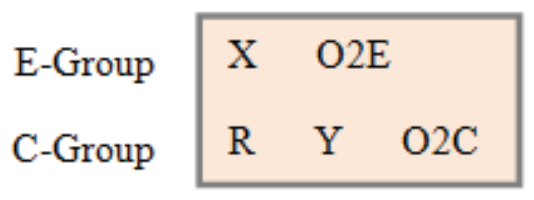

Fig. 1. The Diagram for the experimental design.

\subsection{Tools and Evaluation}

Satisfaction Measurement. The satisfaction level was determined by a questionnaire. The satisfaction results were summarized, as were the mean and standard deviation, in each question. The satisfaction level used the Lickert scale: $5=$ strongly agree, $4=$ agree, $3=$ neutral, $2=$ disagree, and $1=$ strongly disagree. The responses to the five questions in the questionnaire (shown in Table 4) were collected from Google forms completed by students in each class which included the active learning style and the traditional style groups.

Tests and Examination. The examination was set at the end of the course; the test paper had 11 questions (60 points) that were validated by the instructor. The test pa- 
per was used to measure the learning efficiency of the students. The same test was taken by both the groups to measure the learning outcome, with scores from each of the students. The following open questions were used for the exam:

1. Please explain why the Rapid Application Development approach is the best methodology for developing an application. (5 marks)

2. Between the Incremental Model methodology and the Evolutionary Model methodology, which model is more appropriate for small projects, and why. Give an example. (5 marks)

3. Please explain the benefits of using CASE Tools for developing Rapid Application Development. (Give at least 3 examples of CASE Tools.) (5 marks)

4. If you want to develop an application, explain at what point you would begin to design a user interface. (Give at least 4 examples.) (5 marks)

5. Please design (draw and show an idea) the GUIs and suitable function of an application for a senior user who wants to check e-mails. Explain at what point you would begin to design a user interface. ( 5 marks)

6. If you want to design the GUI for the Home Screen section in your application, please explain what at point you would begin to design a user interface. (5 marks)

7. Between list view pattern and card view pattern, which pattern is more appropriate for developing news application, and why. Give an example. (5 marks)

8. Please explain why color on GUIs affects user perception, and why? Give an example. (5 marks)

9. Please explain why we need creative ideas for the development of an application. (5 marks)

10. If we want to develop an application for finding a location, please explain which tools (function and blocks) are needed to be used. ( 8 marks)

11. If we want to develop an application to record sound or store data into the memory of a device, please explain which tools (function and blocks) are needed to be used. (7 marks)

Participants. Based on the experimental design for setting the sample in each group, the experimental group used an active learning style (E-Group) in the classroom. In the classroom setting, both the groups were allowed the use of CASE tools to build a mobile application for an android platform. With App Inventor, the components and blocks are organized into packets that are ready to use.

The traditional learning style is applied by the control group (C-Group) which uses the traditional learning style, while the experimental group has applied the active learning style. The traditional learning style is characterized by having everything done manually, such as giving students various materials. Moreover, the difference in the traditional learning style from the active learning style is that the student only follows the instructor and learns individually.

The experimental design was such that both the traditional learning group and the active learning group had the same instructor for teaching them. The time for learning was set on different dates: the active learning group had lecture and lab on Tuesday morning (08.00-11.00 am), whereas the traditional learning style group had lecture and lab on Friday morning (08.00-11.00 am). 
For the experimental group, the plan for setting the active learning style was as follows: put students in pairs, and send them material, such as graphic files (to build the application), manuals, slides, and other documents electronically via social networks.

To make sure that the communication between the instructors and the students is proactive, a group was created on Facebook for responses, feedback, etc. Each topic or question had a post on a Facebook page for discussion; thereafter, a suitable plan to develop the application was created and each pair of students displayed what they had developed. All the students agreed to connect via a Facebook group page. Figure 2 shows the conceptual design for the active learning environment of the experimental group.

According to the experimental design for setting the sample in each group, experimental group used an active learning style (E-Group) in the classroom. In the classroom setting both groups were allowed to use CASE tools to build a mobile application for an android platform. With App Inventor, the components and blocks are organized into packets that are ready to use.

Traditional learning style is a Control group (C-Group) is using a traditional learning style, while experimental group is using active learning style. Traditional learning style is characterized by having everything done manually such as, giving students various materials. Moreover, the difference of traditional learning style is that student only follows instructor and learns individually.

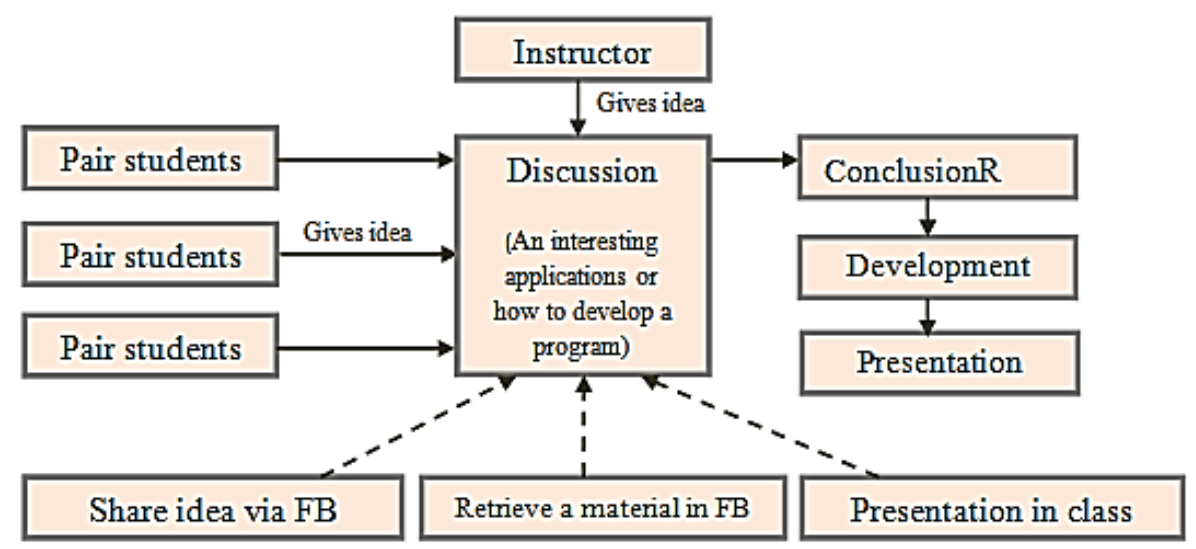

Fig. 2. The conceptual design of the experimental group.

In the classroom, the instructors and the students share ideas to develop interesting applications, and discuss what blocks are used. Each group can debate which program command to use. Figure 3 shows students holding a debate about suitable program commands (blocks) to build an application by each of the groups via Facebook. Figure 4 shows a student debating in front of a computer class and showing her idea; the block editor was presented to the groups to discuss ways to develop the application, whereas on the right side, two students can be seen displaying their application after the debate. 
After the application was fully developed and each of its functions tested, it was presented to the members in the classroom to demonstrate the various functions and explain the blocks in the various parts of the building function. After the presentation, each of the applications was offered to the public on Google Play, which is an online store for android applications. Figure 6 shows examples of the applications, which were published on Google Play Store.

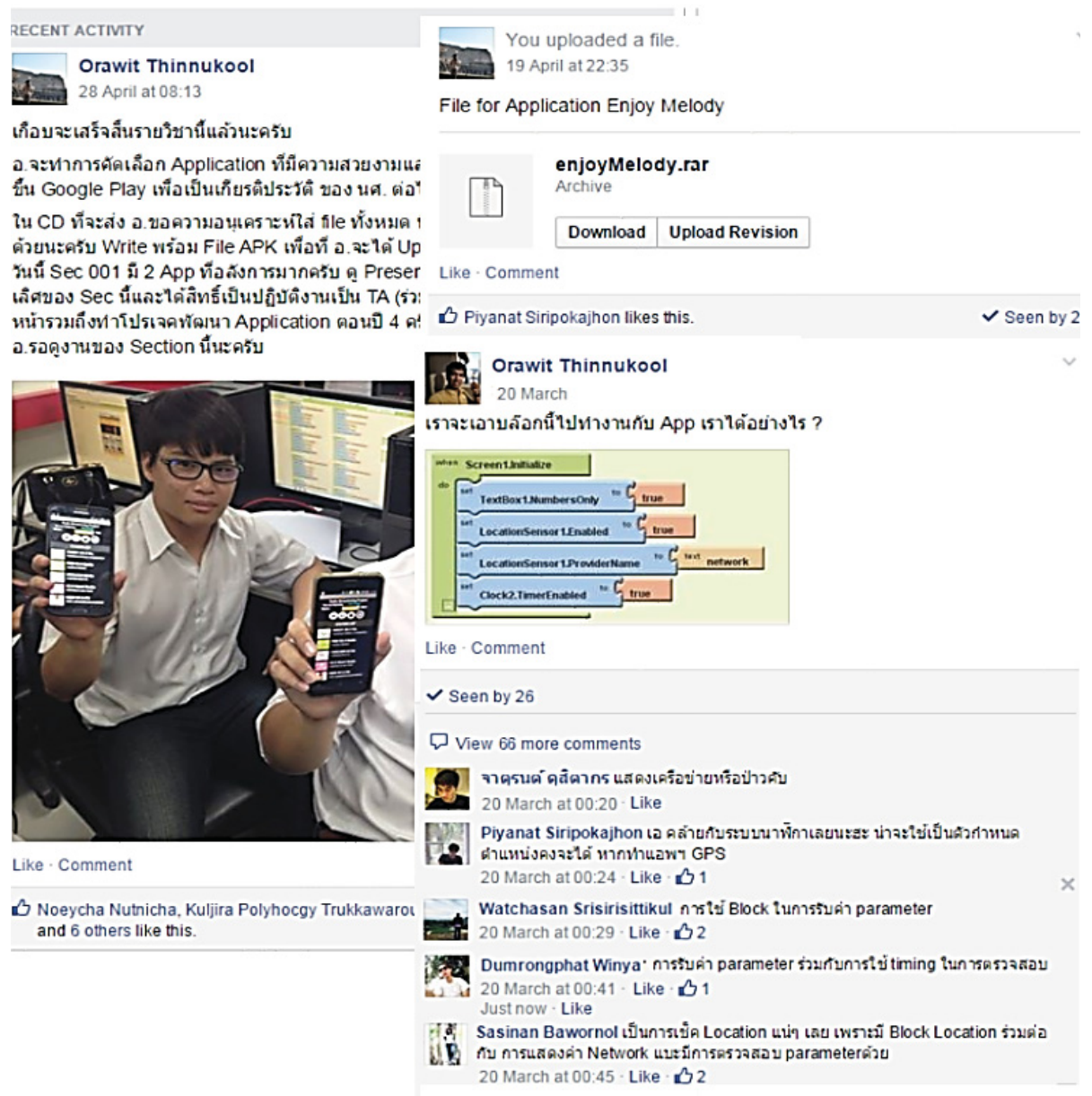

Fig. 3. A snap shot of the social network Facebook's group page, a tool for communication. This page consists of students who are enrolled in the RAD course. 

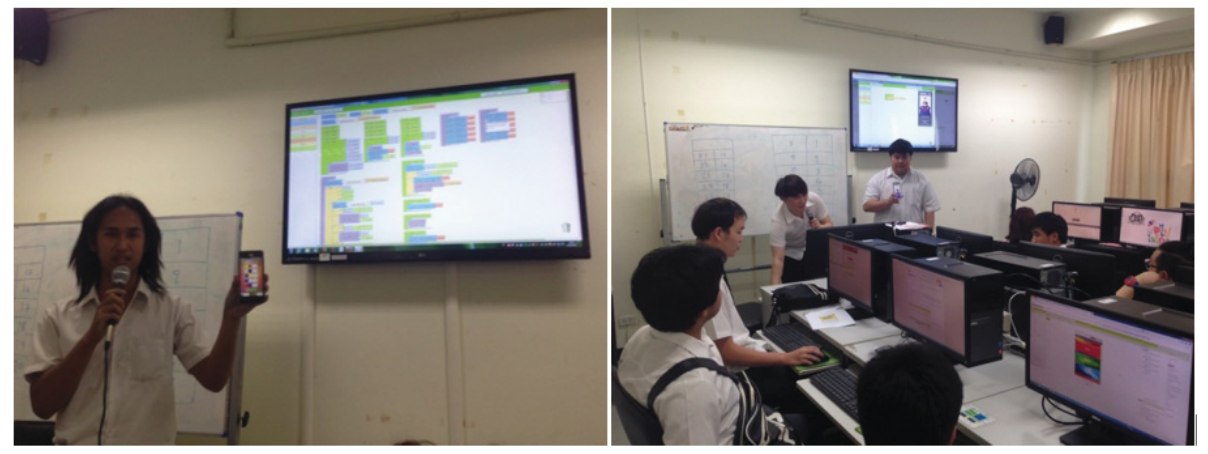

Fig. 4. The picture shows a student debating in front of a class.

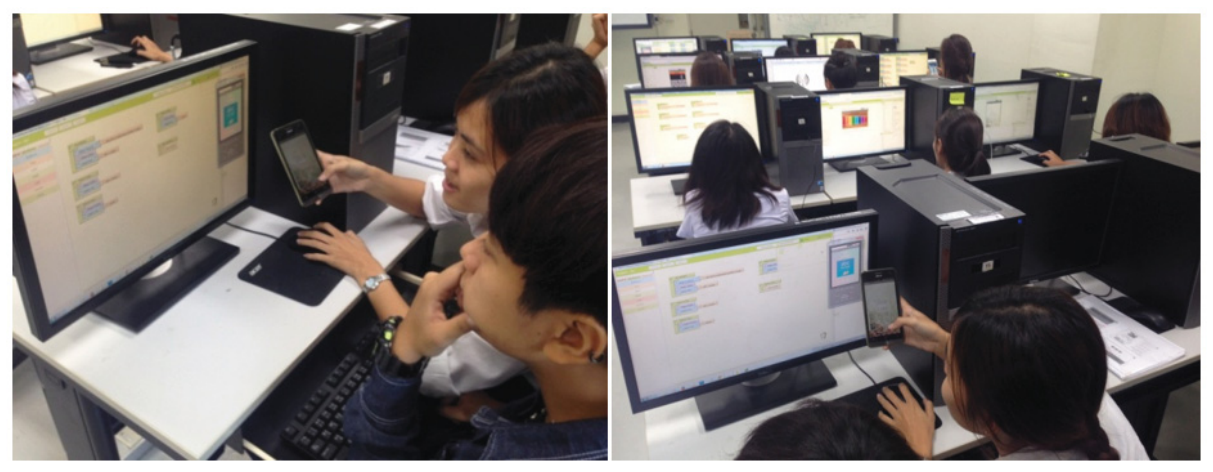

Fig. 5. The environment in RAD classrooms is set so that students can immediately test an application using a phone with the android-based operating system to see the result of the development. Note that android-based mobile devices are popular.

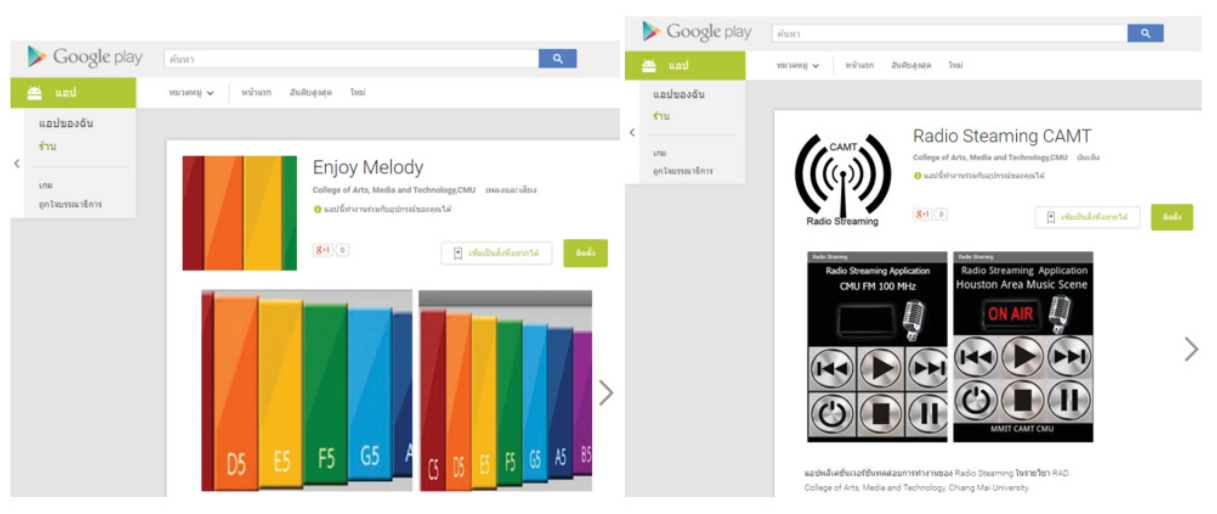

Fig. 6. Examples of applications from a student in an RAD class, available on Google Play Store, which can be downloaded for use directly on an android mobile device, by searching "CAMT application" or simply the name of the application. 
Statistical Analysis. The data were analyzed using descriptive statistics, independent sample t-test, and multiple regression test. T-test assesses whether the means of two groups are statistically different from each other. It is commonly used when the variances of two normal distributions are unknown and an experiment uses a small sample size.

Regression was used to answer the research question, "Do active learning styles influence the GPA score positively more than traditional styles?"

Regression analysis was used to predict the score outcome, where score is the outcome of interest. The formula is follows:

$$
\mathrm{y}=\alpha+\beta(\text { GPA })+\gamma(\text { learning style })+\varepsilon
$$

where $\alpha$ is a constant, and $\beta$ and $\gamma$ indicate the magnitude of GPA and the learning style (active learning $=1$, traditional learning $=0$ ), respectively. $\varepsilon$ is the error of the model when mean $(\mu)$ is zero and the variance is constant $\left(\sigma^{\wedge} 2\right)$. These methods were analyzed by Minitab version 16 .

\section{Results}

\subsection{Learning Efficiency Results}

This research tested the learning efficiency of two groups by comparing the final examination scores, as shown in the result presented in Table 3.

Table 3. Result from Independent T-test Statistical Analysis of Two Types of Learning Styles

\begin{tabular}{|l|c|c|c|c|}
\hline \multicolumn{1}{|c|}{ Group } & mean & sd & t-test & p-value \\
\cline { 1 - 3 } Active leaning & 38.33 & 6.97 & \multirow{2}{*}{1.51} & \multirow{2}{*}{$0.069 *$} \\
\cline { 1 - 3 } Traditional learning & 34.78 & 9.27 & & \\
\hline
\end{tabular}

$$
{ }^{*} \alpha=0.10 \text {. }
$$

The mean score of the 24 students in the active learning group was 38.33 $(\mathrm{sd}=6.97)$, while that of the 25 students who were in the traditional learning group was $34.78(\mathrm{sd}=9.27)$. Since the t-test result equaled 1.25 , and the P-value result equaled 0.069 (one-tail), the hypothesis $\mathrm{H} 0$ was rejected and the hypothesis $\mathrm{H} 1$ : $\mu 1>\mu 2$ was confirmed when the significant level was 0.10 ; the methods did not exhibit statistically significant differences at $\mathrm{p}<0.05$. Thus, it can be concluded that the active learning style did not influence the score positively. Although the hypothesis was rejected, regression analysis was used to test the outcome of the correlation between the two groups.

The experimental results, the results from the tests in the examination of 11 questions (60 points), were validated by the instructor. The scores from each student in both the groups were collected. The examination was used to measure the learning outcome and consisted of open questions. Samples from both the groups were compared to see the differences between active and traditional learning styles. However, the results were analyzed, in which independent samples were used, and the results are shown in Figure 7 in diagram on the right-hand side, whereas the diagram on the diagram on the left-hand side shows that the model has fit well by $\mathrm{R}^{2}=65.6 \%$. 

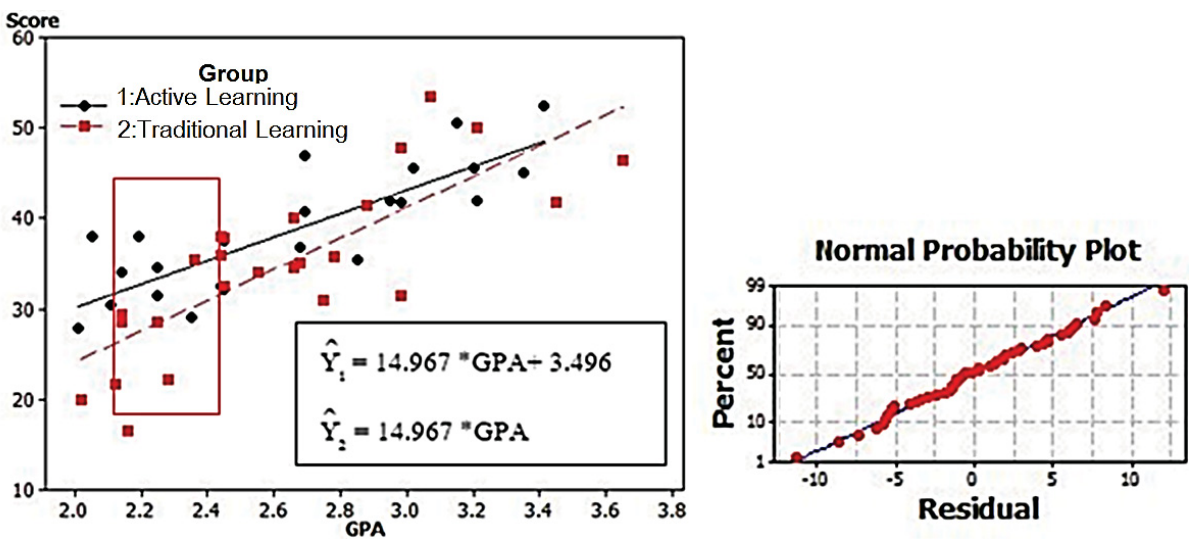

Fig. 7. The regression analysis where the response variable is the score and the predictor variable is GPA and learning style. The diagram on the right-hand side shows the regression model and that on the left-hand side shows the residual normal pp plot.

The result of regression analysis is illustrated using the graph and the equation shown in Figure 7. The solid line represents the active learning group, whereas the dashed line represents the traditional learning group. Moreover, the estimate of the regression coefficient as well as the standard error and the p-values for all the values are given: GPA ( $\beta=14.967, \mathrm{SE}=1.66$, $\mathrm{p}$-value $=0.000$ ), and learning style: active learning $(\gamma=3.496, \mathrm{SE}=1.423, \mathrm{p}$-value $=0.018)$. They were all significant in affecting the test scores and account for about $65.6 \%$ of the variance in the test score.

In addition, GPA and learning style can help predict the examination score. The predicted score from the linear regression model of the active learning style is higher than that from the linear regression model of the traditional learning style which was 3.496. A correlation was found between the GPA and the score in each learning style. Students who had GPA between 2.00 and 2.23 in the active learning group were found to have higher scores than students of the traditional learning group. At the same time, learning style was not found to influence the learning outcome of the students who had GPA in the range of 2.24-4.00.

\subsection{Satisfaction Results}

As observed, high levels of satisfaction in the learning process enhance students' attitude and motivation to pay attention to the instructor or the study material. The result of the satisfaction levels of the two learning styles comes from the satisfaction measurement collected from the student questionnaire which was composed of the questions mentioned in Table 4. Note: The independent t-test results of the satisfaction total scores between the active learning group and the traditional learning group are presented in Table 4. $=0$ (vs $>$ ): t-test $=2.16$, p-value $=0.018$. 
Paper-Is Facebook a Suitable Tool in Modern World Technology for Active Learning in as Regards...

Table 4. Satisfaction Result from Questionnaire That Was Given to Two Groups of Students.

\begin{tabular}{|l|c|c|}
\hline \multicolumn{1}{|c|}{ Criterion } & \multicolumn{2}{c|}{ Mean (sd) } \\
\cline { 2 - 3 } & Active Learning & Traditional learning \\
\hline $\begin{array}{l}\text { S1. Students appreciate the teaching techniques } \\
\text { and tools used in the classroom. }\end{array}$ & $3.83(0.70)$ & $3.56(0.71)$ \\
\hline $\begin{array}{l}\text { S2. The learning style forced the students to } \\
\text { think and analyze the contents of the course. }\end{array}$ & $4.21(0.88)$ & $3.72(0.74)$ \\
\hline $\begin{array}{l}\text { S3. The learning style helped the students to } \\
\text { understand the course content. }\end{array}$ & $3.96(0.69)$ & $3.80(0.65)$ \\
\hline $\begin{array}{l}\text { S4. The laboratory work helped the students to } \\
\text { understand the course content. }\end{array}$ & $4.13(0.68)$ & $3.72(0.68)$ \\
\hline $\begin{array}{l}\text { S5. The learning style allowed the students to } \\
\text { debate or comment in the class. }\end{array}$ & $4.38(0.71)$ & $4.04(0.61)$ \\
\hline Total & $4.10(0.54)$ & $3.77(0.54)^{*}$ \\
\hline
\end{tabular}

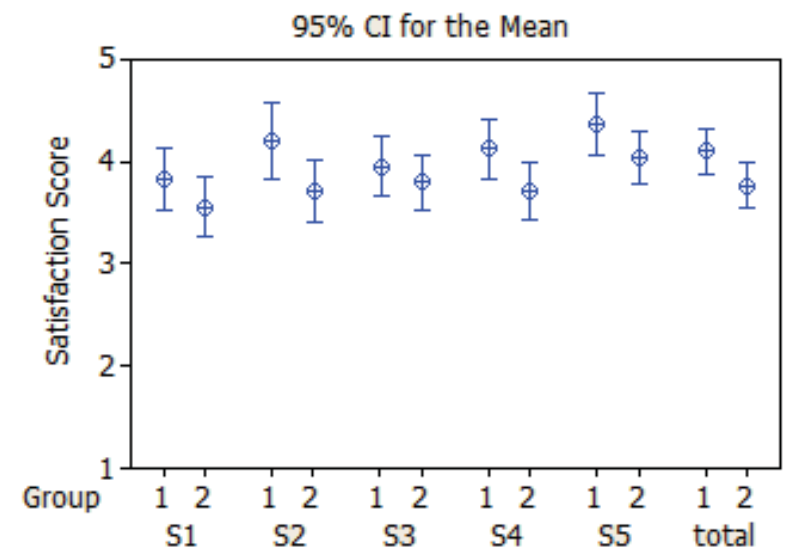

Fig. 8. The $95 \%$ confidence interval of the mean satisfaction score in each item and the total in the two learning styles.

The result shows that the mean scores are $4.10(\mathrm{sd}=0.54)$ and $3.77(\mathrm{sd}=0.54)$ of satisfaction in RAD for the experimental group and the control group, respectively. Upon considering each point, it can be observed that active learning has higher levels of satisfaction. Thus, the satisfaction result of the experimental group was higher than that of the control group. Aside from the questionnaire scores, the comments were collected and are displayed below, noting the learning style of the student who offered the comment:

1. This course is appropriate for non-coding skill students, and provides a good opportunity to build an application besides having a suitable learning style. (Active learning group)

2. This course has a lot of theory, some of which were not used to develop any applications. (Traditional learning group) 
3. The learning style is suitable for students to understand by sharing ideas, and to learn in pairs (Active learning group)

4. The time to practice developing an application was inadequate; if more time was given, ideas could have been shared better (Active learning group)

\section{Discussion}

In this study, two different learning environments were set up to find out which learning style was appropriate for RAD courses. A total of 168 students was picked randomly and separated into two groups. The first group used the traditional style, whereas the second group used the active learning style. The active learning group used a new technology like Facebook as the channel for communication and distribution of course material. The traditional group used the classroom-style face-to-face communication besides using hard copy versions of the course material.

Additionally, the students in the active learning group were working in groups of two, while the students in the traditional style environment were left to work individually. All the same, this experiment had limitations in terms of the sample size that was used in this research study based on assumptions. However, the selected number of students in this study is sufficient as 49 samples were selected from 168 students. This is because the characteristics (GPA) were taken into consideration and the representative of the sample was adequately used in order for it to be a good sample of IT students. It is to be noted that this experiment can be applied to other IT courses if the instructor wants to set up an environment of participation in the classroom.

It was observed that Facebook could be used as a tool to support an active learning environment as well as to encourage students to have motivation for learning in the classroom. It is convenient as it allows sharing of all course materials and has a board for discussion. This tool provides a powerful channel for communication and encourages students to connect with each other. Corresponding to Balakrishana and Lay, it has been confirmed that it is a good tool and is appropriate for students [35], and Levickate agreed that Facebook is a good tool for learning which can be used by university students in a manner similar to other tools [36].

Facebook features, especially, support the active learning style. For instance, pairing students can help students exchange their knowledge, have discussions within a group, and share understanding via the chat function or posting [27]. The active learning style creates the environment for students to effectively develop their skills in remembering, understanding, applying, analyzing, evaluating, and creating.

According to Bloom's taxonomy theory, in terms of affective domain, the connivance in the active learning environment provides an appreciation. For example, any materials in the course or any suggestions or comments that appear on Facebook can encourage students to give an immediate response and indulge in active participation. This environment may also boost student attendance.

In terms of interaction between students and instructors, it was observed that in the traditional group, the students did not interact with the instructor and only expected directions, whereas the students of the active learning group communicated with the 
instructor and with each other a lot. Shyness among the students was observed to have decreased because of Facebook, and the courage to participate in classroom discussions was found to have increased. For these reasons, Facebook can be considered to be a tool that can provide high satisfaction levels in the active learning environment.

The result corresponded to the report by Marsh [37] and Marsh and Roche which confirmed that the factor of student satisfaction is relevant and a valid criterion to be considered when choosing a learning technique [38]. However, a report by Bedggood and Donovan indicates that student satisfaction may or may not have a correlation with the type of learning [39]. Nevertheless, the results from this experiment show that there is association between learning efficiency and student satisfaction.

Upon focusing on learning efficiency, though, it can be seen that the statistical analysis did not exhibit statistically significant differences at $p<0.05$, which indicates that the learning outcomes of the two learning styles did not differ. Even though the learning outcomes from the two learning styles are equivalent, the predicted scores from the linear regression and the students who have GPA between 2.00 and 2.23 show that the active learning style is more likely to help students achieve more in all the aspects investigated in this research study. Thus, new technology such as Facebook may be an appropriate tool more for low GPA students than for high GPA students.

As a result, it cannot be claimed that the result of this study is similar to that of other research studies such as [16][17][31][32]. This is because the learning style did not affect all students, only some of them. Thus, it can only be inferred that learning performance is associated with learning style and GPA, especially for students with low GPA, corresponding to a study by Almigbal, which confirms that learning style may benefit students when an instructor uses the right style of teaching [40]. Learning style can reinforce and encourage students to pay attention by means of various tools, according to the studies by Karpinski and Kirscher and Bosch [41][42]. It confirms that Facebook improves academic performance.

To provide students of the 21 st century with an appropriate learning environment to acquire skill sets as described in the affective domain of Bloom taxonomy, the active learning style, which is also known as learning by doing, is to be set up. This theory shows that students acquire skills more effectively if they are learning by doing. Especially with regard to students with low GPA, the active learning style together with a suitable technology like Facebook can help them learn, share, discuss, and present by setting a positive environment [24].

Based on this experimental research, it can be concluded that active learning is quite a suitable style of learning together with Facebook for Gen Z students who are involved in learning information technology content. The active learning style via a social network can help support active participation of students and provide a useful communication channel between instructors and students [15].

Thus, the outcome of this study may help other instructors to set a suitable classroom environment, especially in IT courses because they can use a laptop computer in a classroom laboratory. 
Paper-Is Facebook a Suitable Tool in Modern World Technology for Active Learning in as Regards...

\section{Conclusion}

Based on the assumptions, the following are the questions addressed: (i) Do active learning styles influence the GPA score more positively than traditional learning styles? (ii) Is the student satisfaction level in the active learning setting higher than in that in the traditional learning style?

In conclusion, the research findings can be summarized as indicating the following:

(i) Learning efficiency, therefore, as well as using Facebook together with other tools, is a great way to create an active learning environment for students of Generation Z, particularly in the field of information technology. According to this study, an instructor has to consider when Facebook is not an appropriate tool for all the students but only for some students in a group (only for low GPA students). Facebook encourages and reinforces students in terms of the learning process by making them participate and communicate with each other in a suitable classroom environment for low GPA groups.

(ii) Learning style and student's satisfaction are key points that are associated with learning outcome and are very much applicable to students in 21 st century learning which requires students to learn by doing. Consequently, up-to-date technology such as Facebook can be considered as a useful tool for students as well.

In future research, to perform useful experiential research, large amounts of data need to be collected. Correlation between timing (how long) and period (morning or afternoon) may be an interesting aspect to consider in further investigations.

\section{References}

[1] Partnership for 21st century skill. Framework for 21st century learning. Retrieved January 3, 2016, from http://www.p21.org/storage/documents/1._p21_framework_2-pager.pdf. [February 2, 2016]

[2] Bloom, B.S., Engelhart, M.D., Furst, E.J., Hill, W.H., and Krathwohl, D.R. (1956). Taxonomy of Educational Objectives, Handbook I: The Cognitive Domain. New York: David McKay Co Inc.

[3] Horovitz, B. (2012). After Gen X, Millennials, what should next generation be. USA Today. Retrieved February 2, 2016, from http://usatoday30.usatoday.com/money/advertising/ story/2012-05-03/naming-the-next-generation/54737518/1 [February 2, 2016]

[4] Lorin, W. A. and David, R. K. (2001). A Taxonomy for Larning, Teaching, and Assessing: A Revision of Bloom's Taxonomy of Educational Objectives. Allyn and Bacon. ISBN 9780-8013-1903-7.

[5] Waldeck J.H. and Dougherty, K. (2010). Collaborative Communication Technology and Learning in College Courses: Which Are Used, for What Purpose, and to What Ends?. Learning, Media and Technology, 37(4), 355-378. https://doi.org/10.1080/17439884. 2011.592497

[6] Turman, C.E. and Schodt, K.A. (2005). Computer-aided Instruction, Media Richness, and College Student Performance. Communication Education, 55(1), 73-104.

[7] Mawdsley, A. (2015). Using Facebook to Support Learning and Exam Preparation in a Final-Year Undergraduate Pharmacy Clinical Therapeutics Module. Currents in Pharmacy Teaching and Learning, 7(6), 869-875. https://doi.org/10.1016/j.cpt1.2015.08.010 
Paper-Is Facebook a Suitable Tool in Modern World Technology for Active Learning in as Regards...

[8] Ogawa, N., and Shimiza, A. (2015). Promotion of Active Learning at National Institute of Technology, Gifu College. Proceedings of the 19th International Conference on Knowledge Based and Intelligent Information and Engineering Systems. Procedia Computer Science, 60, 1186-1194. https://doi.org/10.1016/j.procs.2015.08.180

[9] Coe Regan, J. R., and Freddolino, P. (2008). Integrating Technology into the Social Work Curriculum. Alexandria: CSWE Press.

[10] Chan, J. P., Jae, H. K., Myung, J. K., and Ye, R. Y. (2013). Development of Smart Phone Apps as Active Learning Tools for U-Learning and its Learning Process for Middle School Students. Lecture Notes in Electrical Engineering. 214:851-859. https://doi.org/10.1007/978-94-007-5857-5 92

[11] Tan, Z., Wan, L., Qi, Z., and Wei, R. (2012). Inefficiency of equilibria for the machine covering game on uniform machines. Acta Informatica. 49(6). 261-379. https://doi.org/10.1007/s00236-012-0163-1

[12] Spiro, C. (2006). Generation Y in the Workplace. Defense ATandL. 16-19.

[13] Saraswathi, S. (2011). A Study on Factors that Motivate IT and Non-IT Sector Employees: A Comparison. International Journal of Research in Computer Application and Management, 1(2), 72-77.

[14] Giancola, F. (2006). The Generation Gap: More Myth than Reality. Human Resource Planning, 29(4), 32-37.

[15] Bowman, D. N., and Akcaohlu, M. (2014). I See Smart People: Using Facebook to Supplement Cognitive and Affective Learning in the University Mass Lecture. Internet and Higher Education, 23, 1-8. https://doi.org/10.1016/j.iheduc.2014.05.003

[16] Kabilan, K. M., Ahmad, N., and Abdin, M. J. Z. (2010). Facebook: An Online Environment for learning of English in Institutions of Higher Education. Internet and Higher Education, 13, 179-187. https://doi.org/10.1016/j.iheduc.2010.07.003

[17] Mawdsley, A. (2015). Using Facebook to Support Learning and Exam Preparation in a Final-Year Undergraduate Pharmacy Clinical Therapeutics Module. Currents in Pharmacy Teaching and Learning, 7(6), 869-875. https://doi.org/10.1016/j.cptl.2015.08.010

[18] Munoz, C., and Tower, T. (2009). Opening Facebook: How to Use Facebook in the College Classroom. Society for Information Technology \& Teacher Education International Conference, Mar 02, 2009 in Charleston, SC, USA.

[19] Pempek, T. A., Yermolayeva, Y. A. and Calvert, S. (2009). College Student' Social Network Experience on Facebook. Journal of Applied Developmental Psychology, 30(3), 227238. https://doi.org/10.1016/j.appdev.2008.12.010

[20] Orus, C., Barles, J. M., Belanch, D., Casalo, L., Fraj, E., and Gurrea, R. (2016). The Use of YouTube as a Tool for Learner-Generated Content: Effects on Students' Learning Outcomes and Satisfaction. Computers and Education, In press. https://doi.org/10.1016/j.comp edu.2016.01.007

[21] Bradford, G. R. (2011). A Relationship Study of Student Satisfaction with Learning Online and Cognitive Load: Initial Results. Internet and Higher Education, 14, 217-226. https://doi.org/10.1016/j.iheduc.2011.05.001

[22] Rutz, E. (2003). Learning styles and educational performance Implications for professional development programs. CIEC Conference Proceedings, Tucson, AZ.

[23] Hardesty, L. (2010). The MIT roots of Google's new software. MIT News Office. Retrieved February 2, 2016, from http://news.mit.edu/2010/android-abelson-0819 [February $2,2016]$

[24] Bullard, L., Felder, R., \& Raubenheimer, D. (2008). Effects of Active Learning on Student Performance and Retention. American Society for Engineering Education, 13(473), 1-8.

[25] Tennyson, R. D., and Volkm, A. (2015). Learning Theories and Educational Paradigms. International Encyclopedia of the Social and Behavioural Sciences (Second Edition), 699711. https://doi.org/10.1016/B978-0-08-097086-8.92036-1 
Paper-Is Facebook a Suitable Tool in Modern World Technology for Active Learning in as Regards...

[26] Lorin, A., and David, K. (2001). A Taxonomy for Learning, Teaching, and Assessing: A Revision of Bloom's Taxonomy of Educational Objectives", (Longman; New York, NY).

[27] Herrington, J., and Oliver, R. (2000). An instructional design framework for authentic learning environments. Educational Technology Research and Development, 48(3), 23-48. https://doi.org/10.1007/BF02319856

[28] Leibiger, C. (2016). Types of active-learning techniques. Retrieved on February 2, 2016, from http://libguides.usd.edu/content.php?pid=190434andsid=1597402. [February 2, 2016]

[29] Leong, C. S. U., and Clutter, L. B. (2015). Active Learning Improves Nursing Student Clinical Performance in an Academic Institution in Macao. Chinese Nursing Research, 2, 35-39. https://doi.org/10.1016/j.cnre.2015.08.001

[30] Canaleta, X., Vernet, D., Vicent, L., and Montero, J. A. (2014). Master in Teacher Training: A real implementation of Active Learning. Computers in Human Behaviour, 31, 651658. https://doi.org/10.1016/j.chb.2013.09.020

[31] Park, C., Kang, J., Kim, M., Yu, Y., Kim, H., and Koh, J. (2012). Design and implementation of realtime/non-real-time question-answer apps by using app inventor. Proceedings of the 2012 .

[32] Donald R. P. and Jennifer, L. F. (2015). Active Learning For the College Classroom. California State University, L.A. 5151 State University Drive. Los Angeles, Retrieved March 07, 2015,from http://web.calstatela.edu/ [March 7, 2015]

[33] Paulson, D. R., and Faust, J. L. (2015). Active and cooperative learning. Retrieved March, 3, 2015, from http://www.calstatela.edu/dept/chem/chem2/Active/ [March, 3, 2015]

[34] Balakrishana, V., and Lay, G. C. (2016). Student's learning Styles and Their Effect on the Use of Social Media Technology for Learning. Telemetric and Informatics, 33, 808-821. https://doi.org/10.1016/j.tele.2015.12.004

[35] Levickate, R. (2010). Gereration X, Y, Z: How Social Networks Form the Concept of the World without Borders (the case of Lithuania). Cultural Rationalistic, 3(2), 170-183. https://doi.org/10.3846/limes.2010.17

[36] Marsh, H. (1984). Students Evaluations of University Teaching: Dimensionality, Reliability, Validity, Potential Biases, and Utility. Journal of Education Psychology, 92(1), 202228. https://doi.org/10.1037/0022-0663.92.1.202

[37] Marsh, H., and Roche, L. (2000). Effects of Grading Leniency and Low Workload on Students' Evaluations of Teaching: Popular Myth, Bias, Validity, or Innocent by Standers. Journal of Education Psychology, 92 (1), 202-228. https://doi.org/10.1037/00220663.92.1.202

[38] Bedggood, R., and Donovan, J. (2012). University Performance Evaluations: What Are We Really Measuring. Society for Research into Higher Education, 27(2), 825-842. https://doi.org/10.1080/03075079.2010.549221

[39] Almigbal, T.H. (2015). Relationship between the learning style preferences of medical students and academic achievement. Saudi Medical Journal, 36(3), 349-355. https://doi.org/10.15537/smj.2015.3.10320

[40] Kirschner, P. A., and Karpinski, A. C. (2010). Facebook and Academic Performance. Computers in Human Behaviour, 26 (2010), 1237-1245. https://doi.org/10.1016/ j.chb.2010.03.024

[41] Bosch, T. E. (2009). Using Online Social Network for Teaching and Leaning: Facebook Use at the University of Cap Town. Communication: South African Journal for Communication Theory and Research, 35(2), 185-200. 
Paper-Is Facebook a Suitable Tool in Modern World Technology for Active Learning in as Regards...

\section{$7 \quad$ Authors}

Orawit Thinnukool He received his Ph.D. degree in Research Medthodology from the Prince of Songkla University. His blackground is in information technology, education technology and research operation. Currently, he is a lecturer and a member of the Embedded Systems and Mobile Application Laboratoryand the Department of Modern Management and Information Technologyat the College of Art Media and Technology, Chiang Mai University, Chiang Mai, Thailand.

Noodchanath Kongchouy Her blackground is in statistics and mathtermatics, and research operation. Currently, she is a lecturer in the Department of Mathematics and Statistics, Faculty of Science, Prince of Songkla University, Hat Yai Campus, Songkhla, Thailand.

Article submitted 04 April 2017. Published as resubmitted by the authors 15 June 2017. 